\title{
The Role of Forest Elephants in Shaping Tropical Forest-Savanna Coexistence
}

\author{
Anabelle W. Cardoso, ${ }^{1,2 *} \odot$ Yadvinder Malhi, ${ }^{1}$ Imma Oliveras, ${ }^{1}$ \\ David Lehmann, ${ }^{3,4}$ Josué Edzang Ndong, ${ }^{4}$ Edmond Dimoto, ${ }^{4}$ Emma Bush, ${ }^{3}$

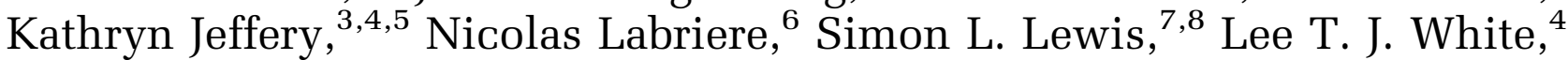 \\ William Bond, ${ }^{9}$ and Katharine Abernethy ${ }^{3,5}$
}

\begin{abstract}
${ }^{1}$ School of Geography and the Environment, University of Oxford, Oxford OX1 3QY, UK; ${ }^{2}$ Department of Ecology and Evolutionary Biology, Yale University, New Haven, Connecticut 06511, USA; ${ }^{3}$ Biological and Environmental Sciences, Faculty of Natural Sciences, University of Stirling, Stirling FK9 4LA, UK; ${ }^{4}$ Agence Nationale des Parcs Nationaux, BP20379, Libreville, Gabon; ${ }^{5}$ Institut de Recherche en Ecologie Tropicale, CENAREST, BP843, Libreville, Gabon; ${ }^{6}$ Laboratoire Évolution et Diversité Biologique, UMR 5174 (CNRS/IRD/UPS), 31062 Toulouse Cedex 9, France; ${ }^{7}$ Department of Geography, University College London, London WC1E 6BT, UK; ${ }^{8}$ School of Geography, University of Leeds, Leeds LS2 9JT, UK; ${ }^{9}$ Biological Sciences Department, University of Cape Town, Cape Town
\end{abstract} 7700, South Africa

\begin{abstract}
Forest edges that border savanna are dynamic features of tropical landscapes. Although the role of fire in determining edge dynamics has been relatively well explored, the role of mega-herbivores, specifically elephants, has not received as much attention. We investigated the role of forest elephants in shaping forest edges of the forestsavanna mosaic in Lopé National Park, Gabon. Using forty camera traps, we collected 1.2 million images between May 2016 and June 2017. These images were classified by over 10,000 volunteers
\end{abstract}

Received 17 December 2018; accepted 14 July 2019; published online 31 July 2019

Electronic supplementary material: The online version of this article (https://doi.org/10.1007/s10021-019-00424-3) contains supplementary material, which is available to authorized users.

Authors' Contribution AC conceived of or designed study, performed research, analyzed data, contributed new methods or models and wrote the paper; YM conceived of or designed study and wrote the paper; IO conceived of or designed study and wrote the paper; DL performed research; JN performed research; ED performed research; EB performed research and wrote the paper; KJ performed research and wrote the paper; NL performed research and wrote the paper; SL performed research and wrote the paper; LW performed research; WB conceived of or designed study and wrote the paper; and KA conceived of or designed study and wrote the paper.

*Corresponding author; e-mail: anabellecardoso@gmail.com through an online citizen science platform. These data were combined with a 33-year phenology dataset on elephant-favoured fruiting tree species, and field measurements of elephant browsing preferences and damage. Our results showed a strong relationship between forest elephant density at the forest edge and fruit availability. When fruit availability was high, elephant density at the edge reached values nearly double the highest densities ever reported in any other part of the landscape (7.5 elephants $\mathrm{km}^{-2}$ in this study vs the previous highest estimate of 4 elephants $\mathrm{km}^{-2}$ ). The highest elephant densities occurred at the end of the dry season, but even outside of this high density period elephant density at the forest edge (2.4 elephants $\mathrm{km}^{-2}$ ) was more than double what other studies estimate for forest interiors with low human hunting pressure (1 elephant $\mathrm{km}^{-2}$ ). We found forest elephants to be selective browsers, but their browsing was non-destructive (in contrast to savanna elephants) and had little effect on tree size demography. Elephant paths acted as firebreaks during savanna burning, making them inadvertent protectors of the fire-sensitive forest and contributing to the stabilising feedbacks that 
allow forest and savanna to coexist in tropical landscapes.

Key words: ecosystem engineer; alternative stable states; forest elephants; Loxodonta cyclotis; fire; forest-savanna mosaic; Gabon.

\section{HighLights}

- Mean forest elephant density at the forest edge is higher than in most of the forest interior areas.

- The forest edge is an important food resource for forest elephants, especially during the dry season.

- Elephant paths at the forest edge act as firebreaks, protecting the interior forest from burning.

\section{INTRODUCTION}

Elephants are the largest living mega-herbivore and have significant impacts on the ecosystems they inhabit. For example, elephants are part of many obligate seed dispersal mutualisms and therefore affect tree recruitment patterns (Campos-Arceiz and Blake 2011).

Elephants also eat and trample established tree seedlings, which impacts species composition and vegetation structure on the local level and ecosystem services such as carbon accumulation and storage at a global scale (Poulsen and others 2013; Terborgh and others 2016). African elephants form two genetically and ecologically distinct groups (Rohland and others 2010; Maisels and others 2013): the savanna elephant, Loxodonta africana (Blumenbach, 1797) and the physically smaller forest elephant, L. cyclotis (Matschie, 1900). Although both African elephant species have faced drastic population declines, recently the most severe of these has been experienced by the forest elephants of Central Africa (Maisels and others 2013; Poulsen and others 2017). What this loss means for ecosystem functionality is not well understood, as relatively little is known about forest elephants relative to savanna elephants (Poulsen and others 2018). A better understanding of forest elephant ecology could galvanise greater support for their urgent protection.

As their name suggests, forest elephants are a forest-dwelling species, with their current range mostly enclosed within the rainforests of Central
Africa (Maisels and others 2013). However, forest elephant density varies significantly across this range (White 1994a). In the absence of human pressure, forest elephant density is largely determined by forage availability (Blake 2002). Fruit is a large component of the forest elephant's diet (White and others 1993), but because fruit availability can be strongly seasonal (White 1994b) there are times when forest elephants may rely more heavily on browse to fulfil their nutritional needs. Accessible browse can be scarce in the understorey of the forest interior, leading elephants to leave the forest interior to seek alternative foraging sites (Blake 2002).

The forest edge, considered in this study to be where closed-canopy forest transitions into opencanopy savanna, may be an important alternative foraging site for forest elephants. The forest edge not only has an abundance of accessible browse, but is also home to multiple elephant-favoured fruiting species (White and others 1993) that may have complementary phenology to the fruit trees in the forest interior. At the end of the long dry season (June-September) in our study site, fruit availability is low in the forest interior, the proportion of fruit in elephant dung is at a minimum, and forest elephants are often "visibly emaciated with only skin on their bones" (White 1992; White and Abernethy 1997; Momont 2007) (Figure S1). It is in this season that we expect forest elephants to preferentially turn to the forest edge as an alternative foraging site. Although forest elephants have been anecdotally observed at forest edges (Momont 2007; Oliveras and Malhi 2016), their use of this specific habitat type and how this use varies through time is yet to be quantified.

If forest elephants are using forest edges as a forage resource, it is likely they are affecting edge dynamics. Forest elephants are known to trample seedlings and snap saplings in the forest interior (Terborgh and others 2016; Rosin and others 2017), whereas savanna elephants target mediumsized trees and cause widespread mortality within savanna (Morrison and others 2015). If forest elephants act in a similar way at the forest edge, then edge contraction may occur. Conversely, if forest elephants disperse seeds and promote tree recruitment at the forest edge (Blake and others 2009), as observed in the forest interior, edge expansion may occur. Forest elephants may also have an indirect stabilising effect on the forest edge, via their interactions with fire. For example, if forest elephants at the forest edge reduce fuel load by eating grass, and decrease fuel continuity by repeatedly trampling paths, they may create firebreaks. These 
firebreaks would prevent fire from spreading from frequently burnt and fire-dependent savanna into the fire-sensitive forest (Hoffmann and others 2003; Mouillot and Field 2005).

How forest elephants affect forest edge dynamics could either mitigate or exacerbate forest encroachment. Forest encroachment, or the loss of savanna area due to expanding forest, is a pressing environmental crisis in tropical ecosystems and is occurring across sub-Saharan Africa (Mitchard and others 2009; Stevens and others 2017). Forest encroachment leads to losses in savanna biodiversity and savanna ecosystem functionality (Parr and others 2014), and preventing it is often a key management objective within protected areas. It has been suggested that savanna elephants could prevent forest encroachment by maintaining or even creating more open landscapes (Asner and Levick 2012). However, whether forest elephants can play a similar structuring role to savanna elephants has not yet been investigated. Gabon, in Central Africa, is a stronghold for forest elephant conservation and is home to most of the remaining global population (Maisels and others 2013), making it the ideal location for such an investigation.

The objective of this study was to quantify forest elephant use of the forest edge, assess the drivers of this use and determine the consequences of this use for forest edge dynamics. We unobtrusively monitored forest elephants at forest edges at high space and time resolution using 40 motion- and heattriggered camera traps. We combined these camera trap data with field measurements of fruit phenology, vegetation structure, and elephant browsing preferences and damage to address the following research questions and hypotheses:

(Q1) Is the forest edge an important forage resource for forest elephants?

$\mathrm{H}_{1.1}$ : Forest elephant density at the forest edge will be higher, or seasonally higher, than previous density estimates made in the forest interior (White 1994a).

$\mathrm{H}_{1.2}$ : Elephant use of the forest edge has distinct seasonal patterns that correlate with seasonal patterns in fruit and browse availability at the forest edge versus in the forest interior.

(Q2) Which species do forest elephants prefer to browse at the forest edge, and is this reflected in these species' size demography?

$\mathrm{H}_{2.1}$ : Forest elephants are selective browsers at the forest edge, showing preferences for certain species and avoiding others.
$\mathrm{H}_{2.2}$ : Forest elephants will prefer to browse on smaller size class stems at the forest edge; therefore, the species on which they prefer to browse $\left(\mathrm{H}_{2.1}\right)$ will have recruited fewer stems into larger size classes compared to species that they avoid browsing on.

(Q3) Is forest elephant activity at the forest edge important for preventing savanna fires from burning into the forest?

$\mathrm{H}_{3.1}$ : Forest elephants' paths at the forest edge that act as firebreaks during savanna burning are more heavily used and have less grass around them than paths that do not act as firebreaks.

\section{MethodS}

\section{Study Site}

Our study site was the forest-savanna mosaic in the northern part of Lopé National Park, Gabon, in central Africa. Here, Middle Ogooué savannas (van de Weghe 2011) interlock with continuous Lower Guineo-Congolian rainforest (White 1983), with sharp transitions or ecotones, between them (Figure S2a). An elephant path is nearly always observed running along the edge of the savanna, parallel to the forest edge (Figure S2b).

Mean annual temperature in LNP is $24{ }^{\circ} \mathrm{C}$ (2003-2016) and mean annual humidity is $81 \%$ (2003-2016) (Tutin and others 2016). Mean annual rainfall is $1442 \mathrm{~mm}$, with mean monthly rainfall ranging between less than $2 \mathrm{~mm}$ in the dry season to more than $150 \mathrm{~mm}$ in the wet season (1984-2016) (Tutin and others 2016). LNP has a short (mid-December to mid-February) and a long (mid-June to mid-September) dry season, with prescribed burning occurring in the latter. Savanna burning has been used as a habitat management tool since 1993 (Jeffery and others 2014) and has been present in the landscape for at least the last 5000 years (White 2001).

\section{Forest Elephant Density}

We estimated forest elephant density at the forest edge at forty sites using motion- and heat-triggered camera traps (Agressor No Glow, Bushnell, Kansas, USA) (Figure 1). At each site, we attached a camera to a tree at $1-1.5 \mathrm{~m}$ above ground. The camera focussed perpendicularly towards the elephant path, so as to be the most likely to capture a passing elephant while also not being in the elephant's way and inciting them to destroy the camera. 


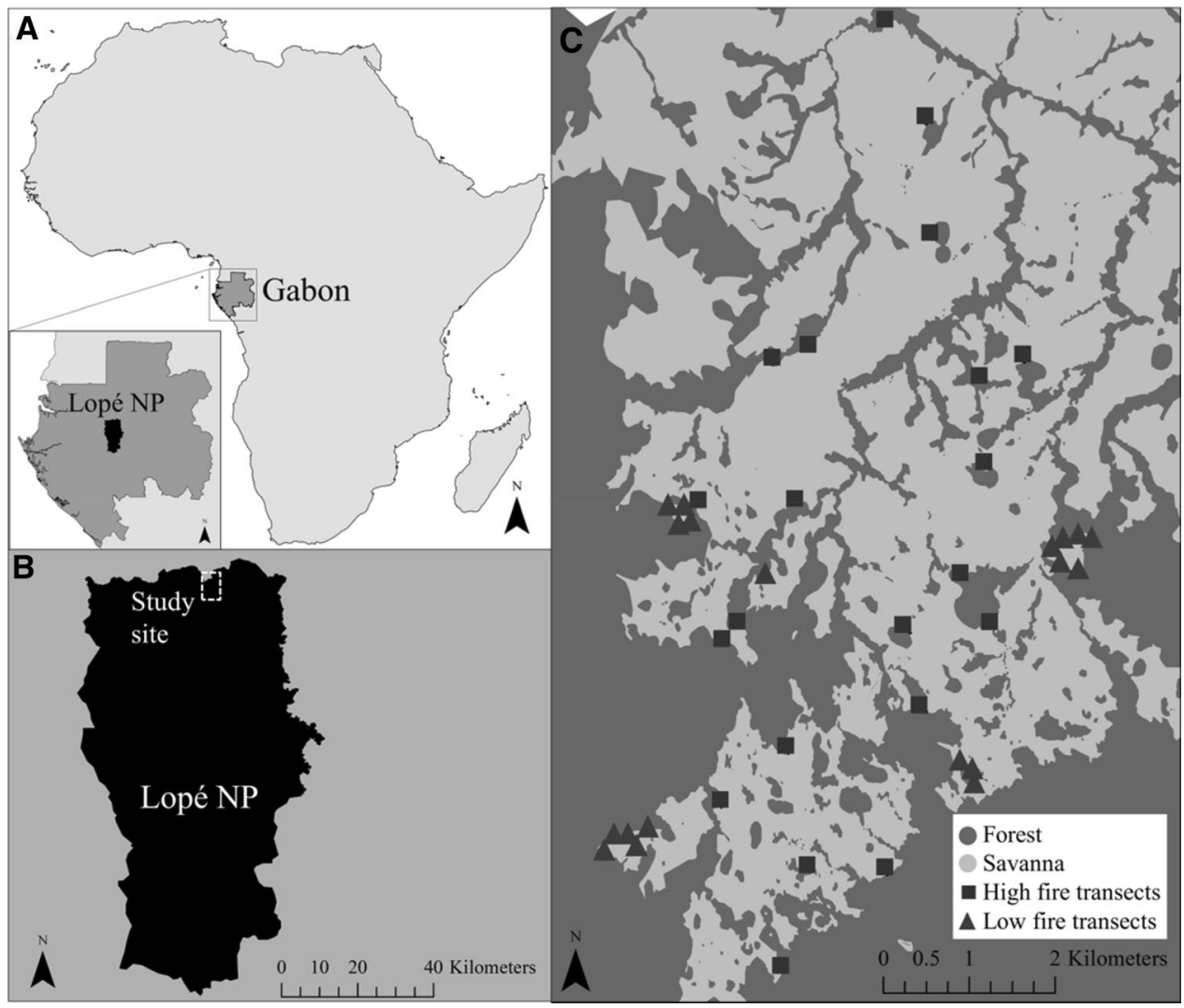

Figure 1. Map showing the location of A Lopé National Park in Gabon, B the study area within the park and $\mathbf{C}$ the 40 camera trap locations across high and low fire frequency sites within the forest-savanna mosaic (Agence Nationale des Parcs Nationaux 2006).

Each camera trap could be triggered up to once per second and was monitored from May 2016 to June 2017, resulting in 1.2 million images being collected. Manual analysis by a small research team was unfeasible. Therefore, we created an interactive web interface ("Elephant Expedition", created in collaboration with Zooniverse.org, available at $\mathrm{h}$ ttps://www.zooniverse.org/projects/anabellecardoso/elephant-expedition, Figure S3), through which more than 10,000 interested members of the public (citizen scientists) classified our images. Each image was classified based on what animal species was in the image, and how many forest elephants were in the image. Images containing animals were each classified by ten volunteers; thus, each image was associated with up to ten potentially conflicting classifications. To assign each image, a single aggregated classification we applied a plurality algorithm (Swanson and others 2015, script available at https://github.com/zooniverse/Data-diggin g/tree/master/example_scripts/R_code/survey-task s/generalized). We assigned the animal species in the image as the one with the highest number of "votes", and the number of elephants in the image as the median count of elephants. Considering that (1) elephants are readily distinguishable from other animals in the study site, (2) images with animals were classified by ten volunteers, (3) the high trigger frequency resulted in multiple images usually being captured during the same elephant visit, we have a high level of confidence in the data obtained from the citizen science classifications (Kosmala and others 2016).

To obtain forest elephant density estimates for each site, we applied a random encounter model (REM) (Rowcliffe and others 2008; Cusack and others 2015) using the formula:

$$
D=\left[\left(\frac{y}{t} \cdot \frac{\pi}{v \cdot r(2+\theta)}\right)\right] * \text { mean group size. }
$$

Here $D$ is the density of elephants (elephants $\left.\mathrm{km}^{-2}\right) \cdot \frac{y}{t}$ is the trapping rate, or total number of independent capture events $(y)$ divided by the total camera effort $(t, h)$. Forest elephants move in cohesive groups and the camera trap can be triggered up to once per second. To avoid counting the same elephant twice we looked for independent 
elephant group capture events. Independent elephant group capture events were peaks in elephant counts separated from other peaks by at least $1800 \mathrm{~s}$ before and after the peak (find_peaks function, available at https://github.com/stas-g/fin dPeaks/blob/master/find_peaks.R). Elephant density was then obtained by multiplying the density of independent group capture events by the mean size of the elephant group (Rowcliffe and others 2008). Mean group size was the sum of peaks in elephant count of all independent group capture events divided by the number of independent group capture events. This is a conservative estimate of group size, as the maximum count of elephants in any one image is the minimum group size. Total camera effort is the number of hours for which the camera was functional. $v$ is the average speed of a forest elephant (a constant $0.334 \mathrm{~km} \mathrm{~h}^{-1}$, Mills and others 2018). $r$ and $\theta$ are the radius ( $(\mathrm{km})$ and angle $\left({ }^{\circ}\right)$ of the camera's detection zone (Rowcliffe and others 2008). We calculated $r$ and $\theta$ by walking in front of the camera detection beam at varying distances and directions and measuring where the trap was triggered. The value applied to $r$ and $\theta$ was then the mean value of a subset of the cameras $(n=17$, mean $r=0.00664 \mathrm{~km}(\max =0.00360 \mathrm{~km}$, $\min =0.01050 \mathrm{~km}) ;$ mean $\theta=28.8^{\circ}\left(\max =40^{\circ}\right.$, $\min =20^{\circ}$.

\section{Browsing Preferences and Damage to Trees}

At each site, we assessed the first 15 trees more than $1 \mathrm{~m}$ tall and less than $1 \mathrm{~m}$ from the elephant path to the right and the left of the camera for elephant damage $(n=1201)$. This assessment was done during the last weeks of camera deployment. We noted tree species and height class (1-2 $\mathrm{m}$ tall, 2-3 $\mathrm{m}$ tall, 3-4 $\mathrm{m}$ tall, more than $4 \mathrm{~m}$ tall), as well as degree of browsing damage (based on Wing and Buss 1970; Ishwaran 1983):

0 . No sign of damage

1. Side branches of canopy broken

2. Main stem/trunk broken

3. Entire tree uprooted

4. Bark stripped

5. Elephant tusk marks on trunk

We calculated preference ratios (Petrides 1975) to assess which species and size class of tree forest elephants preferred to browse on using the formula:

$$
\text { Preference ratio }=\frac{\% \text { damage }}{\% \text { availability }}
$$

where:

$$
\begin{aligned}
& \text { \% damage } \\
& =100 * \frac{\text { number of damaged stems in a species or size class }}{\text { number of damaged stems in all species or size classes }}
\end{aligned}
$$

and:

$$
\begin{aligned}
& \% \text { availability } \\
& \qquad=100 * \frac{\text { number of stems in species or size class }}{\text { number of stems in all species or size classes }}
\end{aligned}
$$

Preference ratios above 1 indicated a species or size class was preferred by elephants, whereas ratios below 1 or 0 indicated that a species or size class was somewhat preferred or avoided by elephants.

We evaluated differences between observed and expected frequencies of trees in different size classes using $\chi^{2}$ tests to assess whether elephants were significantly affecting stem size distribution. Expected frequencies were calculated under the assumption that browsing preferences had no effect on stem size class distribution.

\section{Fruit Phenology}

Fruiting phenology data have been collected at the study site over thirty-three years (1986-2018; Tutin and others 2018). The species in this dataset were originally chosen for their importance in ape diet (Tutin and Fernandez 1993). Fruiting species important to elephants were identified from detailed studies on forest elephant diet at the study site and were found to be highly overlapping with those of ape diets (White and others 1994). Thus, for thirty-one of the thirty-eight species most important to elephants, we have access to thirtythree years of data. For the remaining seven species, data collection began in 1996 or 2001 . Reliable fruiting seasonality can be established with 6 years of data for most species (Bush and others 2017). All species in this study site reproduce annually, except Psychotria vogeliana, Psidium guineensis and Antidesma vogelianum, which flower and fruit every 6 months (Bush and others 2017).

Each month, individual tree crowns were visually monitored and the presence of ripe fruit in the canopy as well as the proportion $(0,0.25,0.5,0.75$, or 1) of the canopy covered by fruit was recorded (see Bush and others 2018 for details on the method). We classified tree species as forest edge species if they occurred in our assessment of elephant damage at the forest edge (described above) and are described in the literature as found most commonly on edges and rarely in the forest interior (White and Abernethy 1997). We classified tree 
species as forest interior species if they did not occur in our elephant damage assessment and were described in the literature as such (White and Abernethy 1997).

Using these data, a fruit availability score (FAS) for the forest edge $\left(\mathrm{FAS}_{\text {edge }}\right)$ and the forest interior

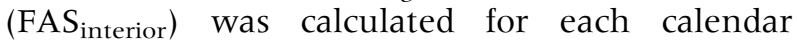
month. The FAS indicates long-term patterns of fruit availability across the landscape. The FAS assumes that the amount of fruit a tree produces scales isometrically with its crown volume, which scales with the square of trunk radius (Shenkin and others, in review). The FAS also assumes that fruit in the canopy is not just present or absent, but that the proportion of the canopy covered in fruit can vary. By adjusting the formula for the "ripe fruit score" (Mitani and others 2002) to account for these assumptions, we calculated the FAS for each habitat type using the formula:

$$
\mathrm{FAS}=\sum_{i=1}^{n} p_{i} * c_{i} * d_{i} * r_{i}^{2}
$$

Here $i$ is the tree species. $p_{i}$ is the mean proportion of individual trees in species $i$ that have ripe fruit in their canopy in any given month. $c_{i}$ is the mean proportion of each fruiting tree canopy that is covered in fruit. $d_{i}$ is the mean density of trees of in species $i$ in that habitat type (forest edge or forest interior) (stems $\left.\mathrm{ha}^{-1}\right) . r_{i}$ is the mean radius at breast height $(\mathrm{cm})$ of trees in species $i$. The mean density and mean radius of each species were determined from existing census data for plots in different habitat types across the study area (Table S1).

We calculated fruit availability scores using longterm phenology data (1986-2018) rather than phenology recorded exclusively during the study period (May 2016-June 2017; but see Figure S4 for the comparison between these two datasets). We assume long-term fruit availability patterns will explain elephant density better than those recorded during the study period because we expect elephants to move across the landscape-based largely on memory, as opposed to current smell, sight and sound cues. Previous work supports this assumption, for example savanna elephants use memory to find the closest water hole from as far away as $50 \mathrm{~km}$, a distance that precludes the use of sight, smell or hearing (Polansky and others 2015). Forest elephants have been shown to exhibit similar abilities in response to Sacoglottis fruiting season, during which they are estimated to be attracted to localised fruiting events from a surrounding area as large as $3000 \mathrm{~km}^{2}$ (White 1994b).

\section{Elephant Paths as Firebreaks}

Twenty-one of the forty camera trap sites were experimentally burnt between July and September 2016 as part of LNP's normal conservation management protocol (Jeffery and others 2014) (Figure 1). Fires were set in the hottest part of the day to maximise intensity. All burning was conducted following appropriate safety protocols, and details on the fires set can be found in Cardoso and others (2018).

At each site, an elephant path ran along the edge of the savanna, parallel to the forest edge. We graded each path as 1 (lightly used, no clear break in the grass layer but clearly trampled), 2 (intermediately used, some bare ground visible but grass still growing on the path) or 3 (heavily used, bare ground clearly visible and clear break in grass layer). After burning, we noted whether or not the elephant path had acted as a firebreak by examining the burn scar and noting where the fire went out (Figure S2).

We assessed grass biomass around the elephant path using a disc pasture meter calibrated for the site (Cardoso and others 2018). Grass biomass measurements were taken (1) at the forest edge, (2) at 1,2 and $3 \mathrm{~m}$ into the savanna and (3) at 1,2 and $3 \mathrm{~m}$ into the forest. Canopy leaf area index (LAI, canopy leaf area per unit ground area) can determine grass biomass (Hoffmann and others 2012), and so was also measured around the elephant path using hemispherical photographs (Nikkor fish-eye lens 10.5 mm F2.8G AF DX IF ED). Photographs were taken (1) in the savanna, $3 \mathrm{~m}$ from the forest edge, (2) at the forest edge and (3) into the forest, $2 \mathrm{~m}$ from the forest edge. Photographs were converted into LAI values using post hoc image analysis in Hemisfer (v2.16, Schleppi and others 2007; Thimonier and others 2010).

We tested for significant differences in grass biomass and LAI between paths that had acted as a firebreak and those that had not using non-parametric Kruskal-Wallis tests. Non-parametric tests were used because the data did not fulfil the assumptions (normality and homoscedasticity) of equivalent parametric tests. 
We performed all analyses in $\mathrm{R}$ (v3.5.0, $\mathrm{R}$ Development Core Team 2018). Significance was noted at $p<0.05$.

\section{RESULTS}

Forest Elephant Density at the Forest Edge was Relatively High $\left(\mathrm{H}_{1.1}\right)$ and was Highest When Fruit was Most Abundant Here $\left(\mathrm{H}_{1.2}\right)$

Mean forest elephant density at the forest edge between May 2016 and June 2017 was $3.1 \pm 0.2$ elephants $\mathrm{km}^{-2}$ (mean \pm standard error) and ranged from $1.3 \pm 0.3$ elephants $\mathrm{km}^{-2}$ (January 2017) to $7.5 \pm 1.4$ elephants $\mathrm{km}^{-2}$ (September 2016) (Figure 2A). Elephant density showed strong seasonal patterns and was highest at the end of the dry season (September to October 2016, 6.7 \pm 1.2 elephants $\left.\mathrm{km}^{-2}\right)\left(\mathrm{H}_{1.1}\right)$ (Figure $2 \mathrm{~A}$ ). As expected, even outside of these exceptionally high density months, mean density at the edge remained relatively high $\left(2.4 \pm 0.4\right.$ elephants $\left.\mathrm{km}^{-2}\right)\left(\mathrm{H}_{1.1}\right)$.

As hypothesised, peaks in forest elephant density coincided with peaks in mean fruit availability at the forest edge, which occurred at the end of the long dry season $\left(\mathrm{H}_{1.2}\right)$ (Figure $2 \mathrm{~B}$ ). Mean forest elephant density at the forest edge had a significant positive relationship with forest edge fruit availability $\left(\mathrm{H}_{1.2}\right)$ (Figure $2 \mathrm{C}$ ). Contrary to our predictions, no significant links were observed between forest elephant density at the forest edge and fruit availability in the forest interior (Figure 2D). However, one of the lowest mean monthly density estimates of forest elephants at the forest edge $\left(2.2 \pm 0.4\right.$ elephants $\mathrm{km}^{-2}$ ) co-occurred (in February 2017) with the forest interior's highest fruit availability score $\left(\mathrm{H}_{1.2}\right)$. Similarly, one of the lowest times for fruit availability in the forest interior cooccurred (in April 2017) with a minor peak in forest elephant density at the forest edge $(2.6 \pm 0.6$ elephants $\left.\mathrm{km}^{-2}\right)\left(\mathrm{H}_{1.2}\right)$.

Forest Elephants are Selective $\left(\mathrm{H}_{2.1}\right)$ but Relatively Non-destructive Browsers, Having No Appreciable Effects on Tree Size Demography $\left(\mathrm{H}_{2.2}\right)$

Over 1200 individual trees from fifty-four species were sampled for elephant damage at the forest edge. Twenty-five of these species had less than five trees sampled and were consequently excluded from the analysis (211 trees). Of the remaining twenty-nine species (1143 trees), nine showed no elephant damage. Of the twenty species that showed some elephant damage, eleven were somewhat preferred (preference ratio between 0 and 1) and nine were strongly preferred (preference ratio $>1$ ) by forest elephants (Table 1).

of the twenty-two species that showed some degree of elephant browsing damage, only six also produced fruit eaten by elephants, and the rest were presumably targeted only for their browse. Of these six species, peaks in elephant density at the forest edge were associated with peaks in fruit availability for Antidesma vogelianum and Sacoglottis gabonensis, both of which were species strongly preferred for browse by forest elephants (Table 1 , Figure S5). Peaks in elephant density were associated to a lesser extent with peaks in fruit availability for the species Psidium guineense, Sarcocephalus latifolius and Psychotria vogeliana, of which the former two were strongly preferred and the latter somewhat preferred by forest elephants.

Less than a fifth $(16 \%)$ of all stems sampled showed some degree of elephant damage. The majority of damage to trees involved branch breaking, followed by main stem snapping (trunk breaking), with uprooting only observed in three trees, of which only one was taller than $2 \mathrm{~m}$ (Figure $3 \mathrm{~A})$. Contrary to our predictions that small size trees would experience more damage, forest elephants in this study were found to preferentially damage medium-sized 3-4 $\mathrm{m}$ tall trees $\left(\mathrm{H}_{2.2}\right)$ (Figure $3 \mathrm{~B})$. Despite this preference, and against our expectations, there were no clear effects of forest elephant browsing preferences in tree size demography, with no significant differences between observed and expected frequencies of trees in each size class or between observed and expected frequencies of trees in each preference category $\left(\mathrm{H}_{2.2}\right)$ (Figure 3C).

\section{The Forest Elephant Paths at the Forest Edge That Acted as Firebreaks Were Those More Heavily Used $\left(\mathrm{H}_{3.1}\right)$}

Of the twenty-one sites that were experimentally burned, sixteen had intermediately (grade 2) and five had heavily (grade 3 ) used elephant paths. No lightly used paths (grade 1) were present. Ten of these twenty-one elephant paths acted as firebreaks at the edge of the savanna during burning. Heavily used paths were more likely to act as firebreaks than intermediately used ones $(80 \%$ of the grade 3 paths vs $38 \%$ of the grade 2 paths acted as firebreaks) $\left(\mathrm{H}_{3.1}\right)$. Although not statistically significant, mean annual elephant density was marginally higher in sites with heavily used paths (grade 3) than those with intermediately used paths 

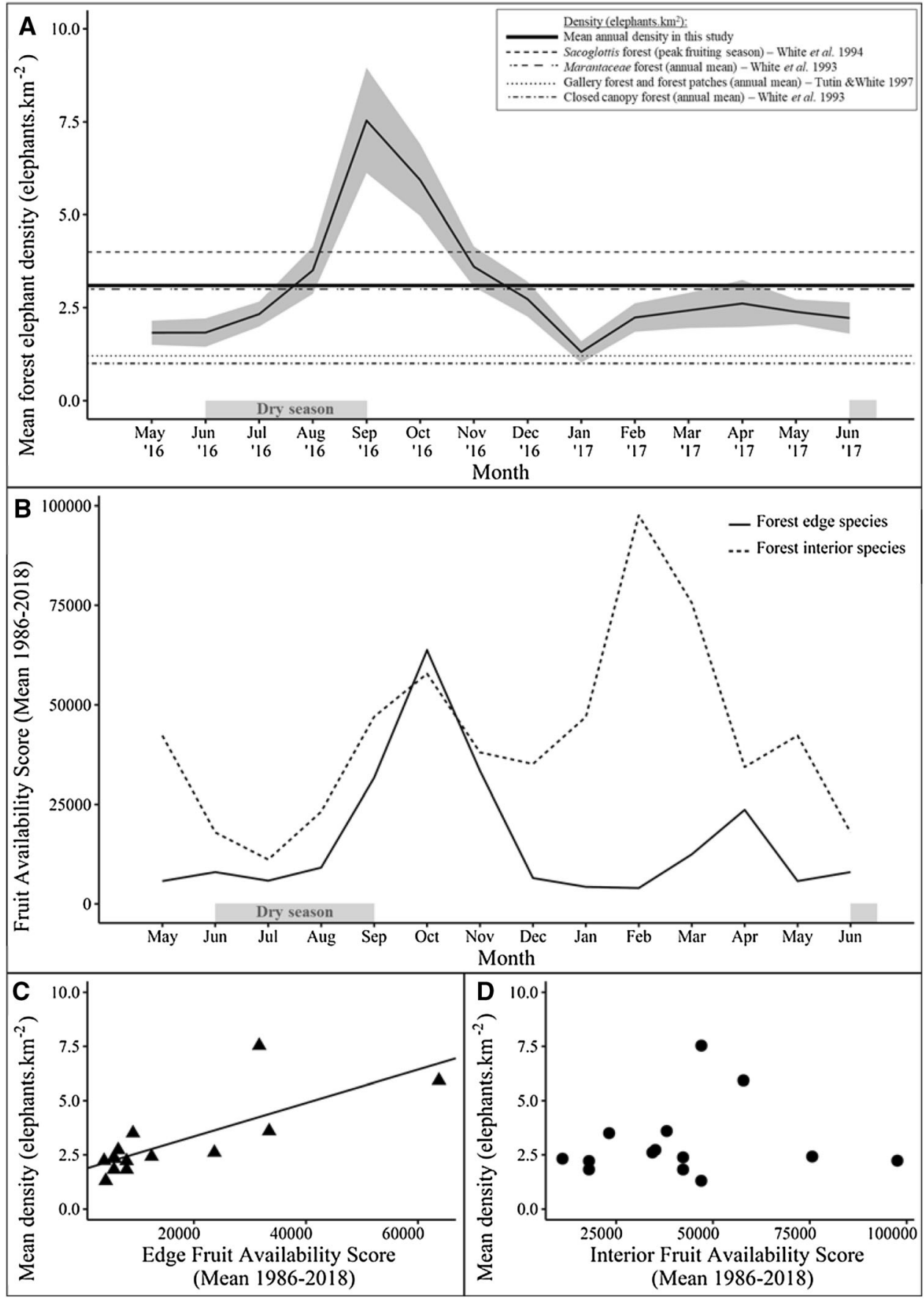

Figure 2. A Mean elephant density at the forest edge (May 2016-July 2017) as calculated from camera traps. Shaded area shows standard error around the mean. Horizontal lines show previously estimated forest elephant densities in other vegetation types in the landscape, as well as the mean annual density in this study. Shaded grey blocks show the long dry season that occurs annually. B Total fruit availability score (monthly mean from 1986 to 2018) for the forest edge and interior. $\mathbf{C}$ and $\mathbf{D}$ Showing the relationship between forest elephant density at the forest edge and fruit availability at the forest edge $(\mathbf{C})$ (linear model, slope $=0.000077$, intercept $=1.8$, adjusted $R^{2}=0.55, p<0.005, d f=12$ ) and the forest interior $(\mathbf{D})$ (linear model, slope $=0.000083$, intercept $=2.7$, adjusted $R^{2}=-0.07, p=0.70, d f=12$ ).

(grade 2) (Kruskal-Wallis, $\chi^{2}=1.75, d f=1$, $p=0.19$; mean ( \pm standard error) annual elephant: sites with grade 3 path $=4.0( \pm 0.8)$ ele- phants $\mathrm{km}^{-2}$, sites with grade 2 path $=2.8( \pm 0.4)$ elephants $\mathrm{km}^{-2}$ ). Paths that acted as firebreaks had marginally less grass biomass around them than 
Table 1. Degree to Which Tree Species At the Forest Edge are Preferred (Preference Ratio $>1$ ), Somewhat Preferred (Preference Ratio $<1$ ) or Avoided (Preference Ratio=0) by Forest Elephants

\begin{tabular}{lrrl}
\hline Species & No. trees sampled & No. trees showing elephant damage & Preference ratio \\
\hline Strongly preferred & & & \\
Holarrhena floribunda & 9 & 4 & 2.78 \\
Sarcocephalus latifolius & 49 & 18 & 2.30 \\
Psidium guineense & 24 & 8 & 2.09 \\
Millettia versicolor & 129 & 38 & 1.84 \\
Antidesma vogelianum & 42 & 10 & 1.49 \\
Vitex doniana & 13 & 3 & 1.44 \\
Crossopteryx febrifuga & 106 & 24 & 1.42 \\
Sacoglottis gabonensis & 84 & 17 & 1.27 \\
Paropsia grewioides & 18 & 3 & 1.04 \\
Somewhat preferred & & & \\
Aidia ochroleuca & 13 & 2 & 0.96 \\
Psychotria vogeliana & 208 & 29 & 0.87 \\
Xylopia aethiopica & 44 & 6 & 0.85 \\
Monanthotaxis congolensis & 19 & 2 & 0.66 \\
Ouratea myrioneura & 82 & 8 & 0.61 \\
Lophira alata & 43 & 4 & 0.58 \\
Cryptosepalum staudtii & 13 & 1 & 0.48 \\
Tetracera podotricha & 13 & 1 & 0.48 \\
Pauridiantha efferata & 14 & 3 & 0.45 \\
Cnestis ferruginea & 54 & 1 & 0.35 \\
Barteria fistulosa & 53 & & 0.12 \\
Avoided & & 0 & \\
Anthocleista vogelii & 7 & 0 & 0 \\
Aucoumea klaineana & 11 & 0 & 0 \\
Cola lizae & 5 & 0 & 0 \\
Diospyros dendo & 27 & 0 & 0 \\
Gomphia flava & 11 & 0 & 0 \\
Manotes sp. & 12 & 0 & 0 \\
Maprounea membranacae & 21 & 5 & 0 \\
Pavetta puberula & 16 & & 0 \\
Psorospermum tenuifolium & 16 & & 0 \\
& & 0 & \\
\hline & & &
\end{tabular}

paths that did not act as firebreaks; however, this difference was not statistically significant (Figure $4 \mathrm{~A})\left(\mathrm{H}_{3.1}\right)$. This marginal difference in grass biomass was not induced by a higher level of shading, as no significant differences in canopy LAI were found between sites where paths had acted as firebreaks and sites where they had not (Figure $4 \mathrm{~B})$.

\section{Discussion}

\section{The Forest Edge is an Important Forage} Resource for Forest Elephants (Q1)

Mean forest elephant density at the forest edge was exceptionally high (7.5 elephants $\mathrm{km}^{-2}$ ) at the end of the long dry season (September 2016). At this time, forest elephant density was approximately double the highest estimate ever made in this landscape (4 elephants $\mathrm{km}^{-2}$ in Sacoglottis gabonensis forest during fruiting season, White 1994b). Forest elephant density at the forest edge remained relatively high (2.4 elephants $\mathrm{km}^{-2}$ ) even outside of the exceptionally high density months at the end of the dry season. This relatively high density of elephants is lower than the previously estimated mean annual density in Marantaceae and colonising forests (3 elephants $\mathrm{km}^{-2}$, White and others 1993), but is more than double the estimated mean annual density in closed-canopy forests that are relatively unaffected by human hunting pressure (1 elephants $\mathrm{km}^{-2}$, White and others 1993; Maisels and others 2013). Differences in methodology may be responsible for some of the differences between elephant density estimates in this study and estimates made in other studies; however, it is not currently possible to quantify the degree to which this is the case. 


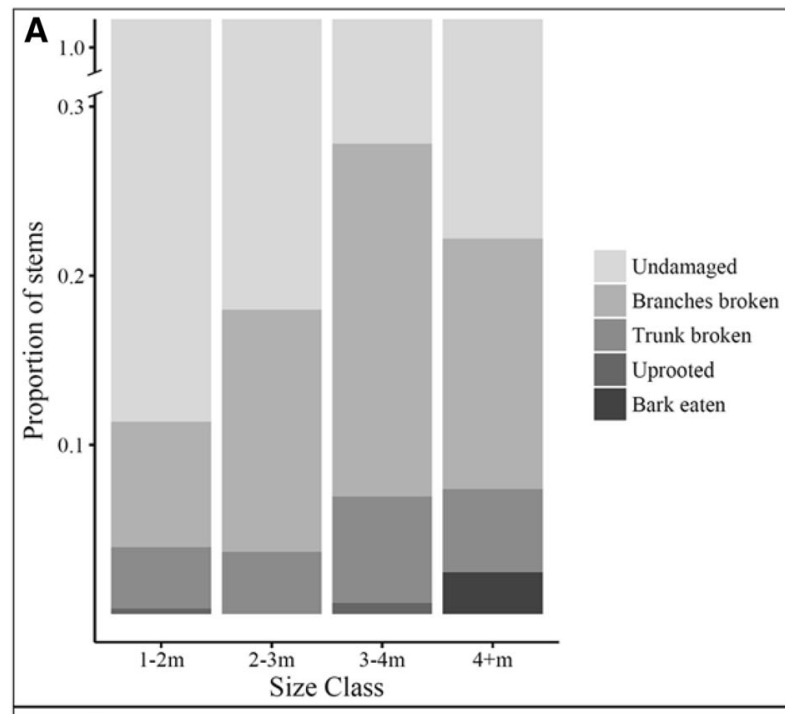

\begin{tabular}{|c|c|c|c|c|}
\hline & $\begin{array}{c}\text { Size } \\
\text { class }\end{array}$ & $\begin{array}{l}\text { No. trees } \\
\text { sampled I }\end{array}$ & $\begin{array}{c}\% \\
\text { Damaged }\end{array}$ & $\begin{array}{c}\begin{array}{c}\text { Preference } \\
\text { ratio }\end{array} \\
\end{array}$ \\
\hline \multirow{4}{*}{ 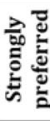 } & $1-2 \mathrm{~m}$ & 208 & 18 & 1.14 \\
\hline & $2-3 \mathrm{~m}$ & 143 & 25 & 1.58 \\
\hline & $3-4 \mathrm{~m}$ & 81 & 43 & 2.70 \\
\hline & $4+m$ & 42 & 38 & 2.38 \\
\hline \multirow{4}{*}{ 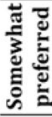 } & $1-2 \mathrm{~m}$ & 363 & 9 & 0.59 \\
\hline & $2-3 \mathrm{~m}$ & 110 & 12 & 0.74 \\
\hline & $3-4 \mathrm{~m}$ & 54 & 17 & 1.04 \\
\hline & $4+m$ & 29 & 7 & 0.43 \\
\hline \multirow{4}{*}{ 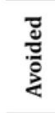 } & $1-2 \mathrm{~m}$ & 63 & 0 & 0.00 \\
\hline & $2-3 \mathrm{~m}$ & 19 & 0 & 0.00 \\
\hline & $3-4 \mathrm{~m}$ & 23 & 0 & 0.00 \\
\hline & $4+m$ & 10 & 0 & 0.00 \\
\hline
\end{tabular}

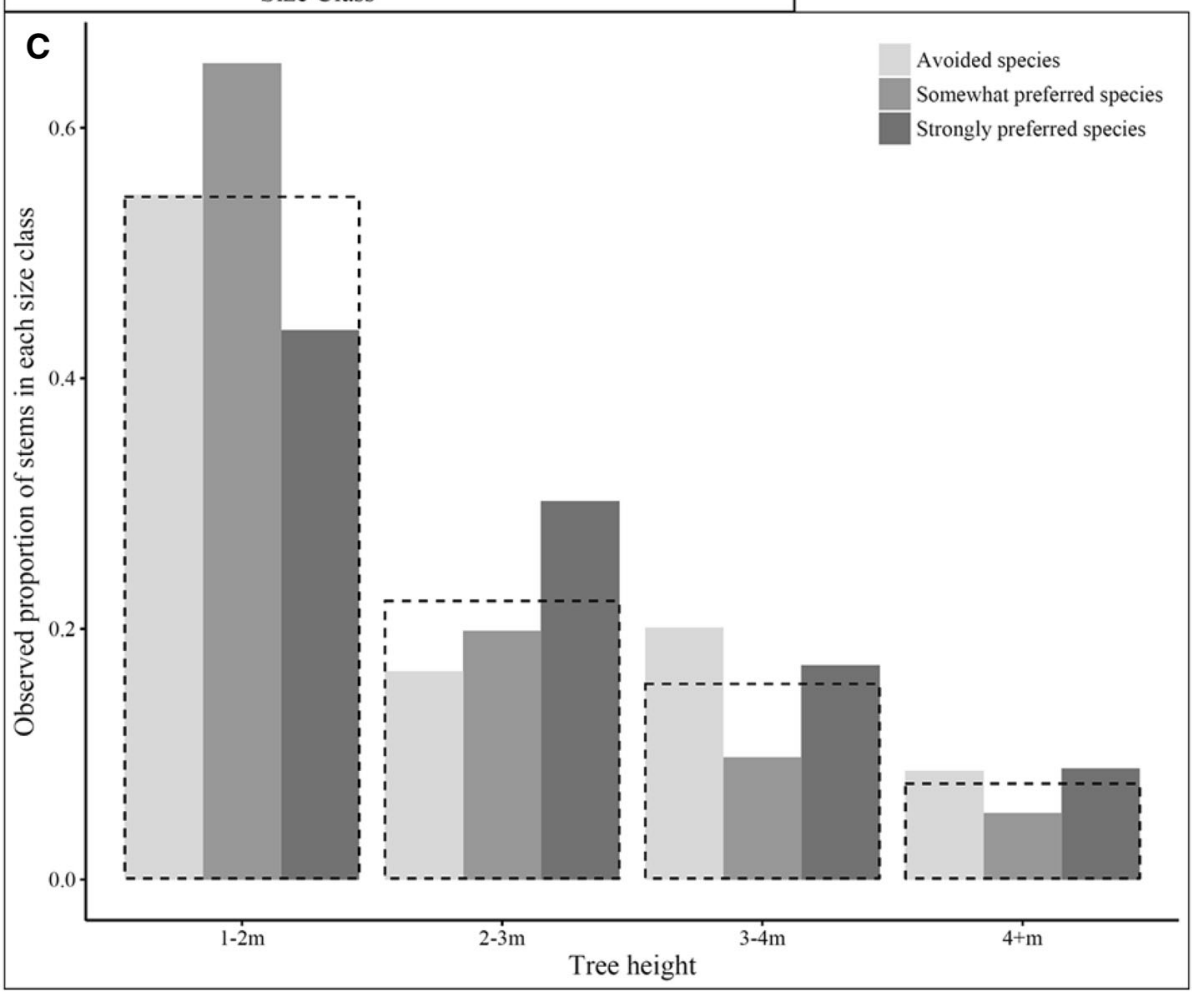

Figure 3. A Proportion of trees in each size class incurring different types of forest elephant damage. Note that the $y$-axis has been compressed for display purposes. B Table of which size class trees forest elephants prefer to browse in each preference categories of species. C Size distribution of trees for species avoided, somewhat preferred and strongly preferred by forest elephants. No significant differences were found between observed (different shaded bars) and expected (dotted lines) frequencies of stems in each size class, or between frequencies of stems in each preference categories (in $\chi^{2}$ tests $p$ was always $>0.5$ ).

The relatively high density of forest elephants at the forest edge throughout the year provides compelling evidence that the edge is a key resource for these elephants. Due to the abundance of forest edges in forest-savanna mosaics, this finding may also explain why previous work has found forest- savanna mosaics to be such a heavily utilised part of the forest elephants' range. For example, Momont (2007) showed four collared female forest elephants to prefer the forest-savanna mosaic to the closed-canopy forest. Mills and others (2018) found similar patterns and indicated that conser- 


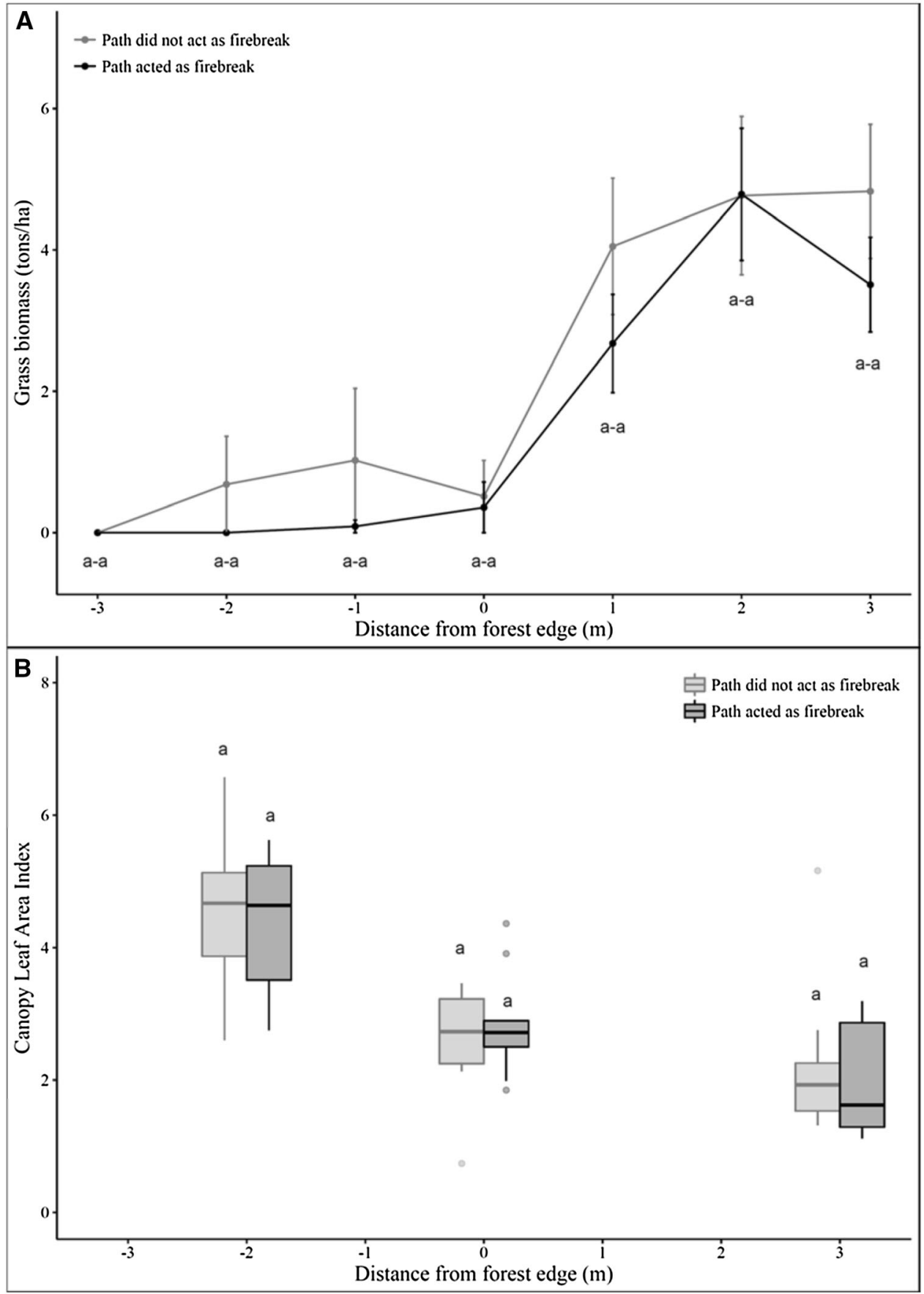

Figure 4. A Grass biomass and B tree canopy cover (leaf area index, LAI) around the forest elephant path that runs along the edge of the savanna, parallel with the edge of the forest. Positive distances from the forest edge are in the savanna, negative distances in the forest. Different letters indicate significant differences between sites where the path acted as a firebreak versus those in which it did not as determined by Kruskal-Wallis tests $(p<0.05)$.

vation of the forest-savanna mosaic should be a priority for this reason. Furthermore, Maisels and others (2013) found that forest elephant density was higher near the forest-savanna mosaic of our study site than anywhere else in Africa.
The importance of the forest edge to forest elephants is further illustrated by the exceptionally high elephant density that occurred at the end of the long dry season, when fruit availability at the edge was highest. The end of the long dry season is anecdotally when the elephants are struggling the 
most to meet their nutritional needs (White 1994b; White and Abernethy 1997), and as such any fruit available to the elephants during this time is likely to be essential for their wellbeing. The exceptionally high density of elephants during this time also suggests that forest elephants are being attracted to the forest edge from a wide area, indicating the importance of this habitat type for elephant populations across the landscape. This conclusion is supported by previous work by White (1994b), which estimated that forest elephants were attracted to a fruiting event from an area fifteen times the size of the area where the event occurred.

\section{Forest Elephants are Selective Browsers, However This Browsing is Relatively Non-destructive and Not Reflected in Tree Size Demography (Q2)}

The forest edge seems to be an attractive resource to forest elephants for browse as well as for fruit, with many species not producing elephant-preferred fruits but still exhibiting signs of elephant browsing damage. Forest elephants did not browse all species of the forest edge equally and showed a strong preference for some species while avoiding others, as is observed for savanna elephants (Owen-Smith and Chafota 2012). At least one of the tree species most favoured by forest elephants, Millettia versicolor, seems to be resistant to their browsing, being documented to have a strong coppicing ability (White and Abernethy 1997). A coppicing response to herbivory has been documented in more arid savanna tree species (Staver and others 2012) and, however, has not yet been explored for more mesic forest-savanna transition species. This is thus an interesting topic for future research.

Forest elephants preferred to browse on larger trees (3-4 m tall), similarly to savanna elephants who browse extensively on trees $>2 \mathrm{~m}$ tall (Morrison and others 2015). In systems with savanna elephants, this preference leads to largescale tree mortality (Morrison and others 2015) and a dearth of trees in larger size classes (Asner and others 2009). However, this study showed forest elephants to have no detectable effects on tree size demography, likely because the overall level of damage to trees was relatively low. Damage to larger trees by elephants may be even less severe than estimated here, as we did not take into account that larger trees are usually older and have had more time to accumulate damage, and that some damage may be the result of browsing by other species, specifically large apes.
Previous studies on elephant damage to trees have mostly come from systems dominated by savanna elephants. For example, savanna elephants have been observed to inflict damage on up to $90 \%$ of trees taller than $2 \mathrm{~m}$ (Morrison and others 2015), while in our study, trees of the same size class were only damaged by forest elephants $28 \%$ of the time. The estimates of elephant damage in this study (16\% of all stems sampled) are also lower than estimates of forest elephant damage in the forest interior from Terborgh and others (2016) (ca. 50\% of all stems $2-6 \mathrm{~cm}$ diameter at breast height). However, direct comparison is difficult since Terborgh and others (2016) did not provide the height of the stems sampled and did not sample stems smaller than $2 \mathrm{~cm}$ diameter at breast height. Nevertheless, these comparisons highlight the stark differences not only between forest and savanna elephants, but also between forest elephants foraging in different habitats.

Elephants are often assumed to be able to prevent forest encroachment into open-canopied savanna. For example, modelling studies predict how much more open tropical landscapes would be without the widespread loss of mega-fauna (Doughty and others 2015). Specifically, the widespread extirpation of elephants is cited as a key contributor to forest expansion in Africa between the Pleistocene and Holocene (Owen-Smith 1987). The assumption that elephants are important for maintaining and creating open landscapes is based on work done on savanna elephants, who frequently fell canopy-size trees and can be the leading cause of large tree mortality (Asner and Levick 2012; Morrison and others 2015). This study, however, demonstrates that tree-felling may be a uniquely savanna elephant behaviour. That forest and savanna elephants have a non-interchangeable ecological functional lends support to the argument that they should be considered as separate species in conservation policies (for example, by the IUCN (2018)).

\section{Forest Elephant Activity at the Forest Edge is Important for Preventing Savanna Fires from Burning into the Forest (Q3)}

The forest interior was protected from burning by the forest elephant path at the forest edge acting as a firebreak in approximately half of the experimental fires. To accomplish this ecosystem function, paths needed to be heavily used, with intermediately used paths being only half as effective. From a conservation perspective, this highlights the importance of maintaining high forest 
elephant density within forest-savanna mosaics, as smaller populations are likely incapable of fulfilling this ecosystem function. Although it is possible that other animals contribute to the maintenance of heavily used paths, at our study sites elephants are the mammal species with the greatest cumulative biomass by far (White 1994a) and thus we assume them to play the biggest role in path maintenance. We recommend that the conclusions from this study are tested at forest edges that have no elephant paths or where elephants are locally extinct. Such locations are rare in LNP and were thus not able to be included in this study.

The discontinuity in fuel introduced by a wider, more heavily used, elephant path was a key determinant of whether a path acted as a firebreak or not. In contrast, grass biomass and tree canopy cover were not found to be important factors. However, fuel discontinuity alone is not enough to stop fires, as evidenced by our field observations that heavily used elephant paths in the savanna interior never act as firebreaks (Figure S6). Previous work has shown that fires are significantly less intense nearer the forest edge than in the savanna interior (Cardoso and others 2018). We thus conclude that both reduced intensity and discontinuity in fuel are essential for forming a firebreak at the forest edge.

\section{ConClusion}

Forest elephants are exceptionally abundant at the forest edge. The forest edge is an important part of the forest elephant's range, providing both fruit and browse resources to them. Forest elephants forage relatively non-destructively compared to their savanna relatives. Thus, the maintenance and creation of open-canopied landscapes in Central Africa remains primarily the role of fire. However, forest elephants' heavily used paths along the edge act as firebreaks and prevent fire from reaching the forest interior. Forest elephants thus provide a valuable ecosystem service by reinforcing the firerelated feedbacks that allow forest and savanna to coexist, and have likely stabilised mosaicked landscapes through time.

\section{ACKNOWLEDGEMENTS}

Agence Nationale des Parcs Nationaux (ANPN), ANPN director of science Dr A.F.K. Pambo and ANPN field assistants G.A. Kamba, J. Dibakou, A.D. Bousseba, N.E. Milamizokou, P.A. Dimbonda, M.C. Koumba, B. Moussavou and S. Nzoma. All Elephant Expedition volunteers, especially moderators
M. Rees and J. Widness. The Zooniverse.org team, especially C. Allen, A. Swanson, G. Miller and M. Willi. N. Owen-Smith, J. Cusack and P. Henschel for helpful discussion. Project research expenses and AWC were supported by the U.Oxford's Hertford Mortimer-May scholarship; AWC was also supported by the Commonwealth Scholarship Commission and the Oppenheimer Fund; KA, KJ and DL were supported by the U.Stirling; KJ and JEN by ANPN; YM was supported by ERC grant ERC-2013-AdG-321131-GEMTRAITS, and YM also by the Jackson Foundation.

\section{Compliance with Ethical Standards}

Conflict of interest The authors declare that they have no conflict of interest.

\section{OPEN ACCESS}

This article is distributed under the terms of the Creative Commons Attribution 4.0 International License (http://creativecommons.org/licenses/by/4 $.0 /$ ), which permits unrestricted use, distribution, and reproduction in any medium, provided you give appropriate credit to the original author(s) and the source, provide a link to the Creative Commons license, and indicate if changes were made.

\section{REFERENCES}

Agence Nationale des Parcs Nationaux. 2006. Forest-savanna cover derived from $30 \mathrm{~m}$ AVHRR Radar imagery, INTerra 1998 updated with ground measurement 2006. SEGC Map Database.

Asner GP, Levick SR. 2012. Landscape-scale effects of herbivores on treefall in African savannas. Ecol Lett 15:1211-17.

Asner GP, Levick SR, Kennedy-Bowdoin T, Knapp DE, Emerson R, Jacobson J, Colgan MS, Martin RE. 2009. Large-scale impacts of herbivores on the structural diversity of African savannas. Proc Natl Acad Sci U S A 106:4947-52.

Blake S. 2002. The Ecology of Forest Elephant Distribution and its Implications for Conservation- A thesis submitted for the degree of PhD.:319.

Blake S, Deem SL, Mossimbo E, Maisels F, Walsh P. 2009. Forest elephants: tree planters of the Congo. Biotropica 41:459-68.

Bush ER, Abernethy KA, Jeffery K, Tutin C, White L, Dimoto E, Dikangadissi JT, Jump AS, Bunnefeld N. 2017. Fourier analysis to detect phenological cycles using long-term tropical field data and simulations. Methods Ecol Evol 8:530-40.

Bush ER, Bunnefeld N, Dimoto E, Dikangadissi JT, Jeffery K, Tutin C, White L, Abernethy KA. 2018. Towards effective monitoring of tropical phenology: maximizing returns and reducing uncertainty in long-term studies. Biotropica 50:45564.

Campos-Arceiz A, Blake S. 2011. Megagardeners of the forest-the role of elephants in seed dispersal. Acta Oecologica 37:542-53. 
Cardoso AW, Oliveras I, Abernethy KA, Jeffery KJ, Lehmann D, Edzang Ndong J, McGregor I, Belcher CM, Bond WJ, Malhi YS. 2018. Grass Species Flammability, Not Biomass, Drives Changes in Fire Behavior at Tropical Forest-Savanna Transitions. Front For Glob Chang 1:6.

Cusack JJ, Swanson A, Coulson T, Packer C, Carbone C, Dickman AJ, Kosmala M, Lintott C, Rowcliffe JM. 2015. Applying a random encounter model to estimate lion density from camera traps in Serengeti National Park, Tanzania. J Wildl Manage 79:1014-21.

Doughty CE, Faurby S, Svenning JC. 2015. The impact of the megafauna extinctions on savanna woody cover in South America. Ecography (Cop) 38:1-10.

Hoffmann WA, Geiger EL, Gotsch SG, Rossatto DR, Silva LCR, Lau OL, Haridasan M, Franco AC. 2012. Ecological thresholds at the savanna-forest boundary: how plant traits, resources and fire govern the distribution of tropical biomes. Ecol Lett 15:759-68.

Hoffmann WA, Orthen B, Vargas Do Nascimento PK. 2003. Comparative fire ecology of tropical savanna and forest trees. Funct Ecol 17:720-6.

Ishwaran N. 1983. Elephant and woody-plant relationships in Gal Oya, Sri Lanka. Biol Conserv 26:255-70.

IUCN. 2018. The International Union for Conservation of Nature Red List of Threatened Species. http://www.iucnredlist.org. Last accessed 22/08/2018

Jeffery KJ, Korte L, Palla F, White LJT, Abernethy Ka. 2014. Fire Management in a Changing Landscape: a case study from Lopé National Park. Parks 20:35-48.

Kosmala M, Wiggins A, Swanson A, Simmons B. 2016. Assessing data quality in citizen science. Front Ecol Environ 14:551-60.

Maisels F, Strindberg S, Blake S, Wittemyer G, Hart J, Williamson EA, Aba'a R, Abitsi G, Ambahe RD, Amsini F, Bakabana PC, Hicks TC, Bayogo RE, Bechem M, Beyers RL, Bezangoye AN, Boundja P, Bout N, Akou ME, Bene LB, Fosso B, Greengrass E, Grossmann F, Ikamba-Nkulu C, Ilambu O, Inogwabini B-I, Iyenguet F, Kiminou F, Kokangoye M, Kujirakwinja D, Latour S, Liengola I, Mackaya Q, Madidi J, Madzoke B, Makoumbou C, Malanda G-A, Malonga R, Mbani O, Mbendzo VA, Ambassa E, Ekinde A, Mihindou Y, Morgan BJ, Motsaba P, Moukala G, Mounguengui A, Mowawa BS, Ndzai C, Nixon S, Nkumu P, Nzolani F, Pintea L, Plumptre A, Rainey H, de Semboli BB, Serckx A, Stokes E, Turkalo A, Vanleeuwe H, Vosper A, Warren Y. 2013. Devastating decline of forest elephants in central Africa. PLoS One 8:e59469.

Mills EC, Poulsen JR, Fay JM, Morkel P, Clark CJ, Meier A, Beirne C, White LJT. 2018. Forest elephant movement and habitat use in a tropical forest-grassland mosaic in Gabon. PLoS One:1-17.

Mitani JC, Watts DP, Lwanga JS, Marchant L. 2002. Ecological and social correlates of chimpanzee party size and composition. In: Boesch C, Hohmann G, Marchant L, editors. Behavioural Diversity in Chimpanzees and Bonobos. Cambridge University Press. pp 102-11.

Mitchard ET, Saatchi SS, Gerard FF, Lewis SL, Meir P. 2009. Measuring Woody Encroachment along a Forest-Savanna Boundary in Central Africa. Earth Interact 13:1-29.

Momont L. 2007. Sélection de l'habitat et organisation sociale de l'éléphant de forêt, Loxodonta africana cyclotis (Matschie 1900), au Gabon.

Morrison TA, Holdo RM, Anderson TM. 2015. Elephant damage, not fire or rainfall, explains mortality of overstorey trees in Serengeti. J Ecol 104:409-18.
Mouillot F, Field CB. 2005. Fire history and the global carbon budget: a lox lo fire history reconstruction for the 20th century. Glob Chang Biol 11:398-420.

Oliveras I, Malhi Y. 2016. Many shades of green: the dynamic tropical forest-savannah transition zones. Philos Trans R Soc B Biol Sci 371:20150308.

Owen-Smith N. 1987. Paleontological Society Pleistocene Extinctions: the Pivotal Role of Megaherbivores. Paleobiology 13:351-62.

Owen-Smith N, Chafota J. 2012. Selective feeding by a megaherbivore, the African elephant (Loxodonta africana). J Mammal 93:698-705.

Parr CL, Lehmann CER, Bond WJ, Hoffmann Wa, Andersen AN. 2014. Tropical grassy biomes: misunderstood, neglected, and under threat. Trends Ecol Evol 29:205-13.

Petrides GA. 1975. Principal foods versus preferred foods and their relations to stocking rate and range condition. Biol Conserv 7:161-9.

Polansky L, Kilian W, Wittemyer G. 2015. Elucidating the significance of spatial memory on movement decisions by African savannah elephants using state - space models. Proc R Soc B Biol Sci 282.

Poulsen JR, Clark CJ, Palmer TM. 2013. Ecological erosion of an Afrotropical forest and potential consequences for tree recruitment and forest biomass. Biol Conserv 163:122-30.

Poulsen JR, Koerner SE, Moore S, Medjibe VP, Blake S, Clark CJ, Akou ME, Fay M, Meier A, Okouyi J, Rosin C, White LJT. 2017. Poaching empties critical Central African wilderness of forest elephants. Curr Biol 27:R134-5.

Poulsen JR, Rosin C, Meier A, Mills E, Nuñez CL, Koerner SE, Blanchard E, Callejas J, Moore S, Sowers M. 2018. Ecological consequences of forest elephant declines for Afrotropical forests. Conserv Biol 32:559-67.

R Development Core Team. 2018. R: A language and environment for statistical computing. http://www.r-project.org.

Rohland N, Reich D, Mallick S, Meyer M, Green RE, Georgiadis NJ, Roca AL, Hofreiter M. 2010. Genomic DNA sequences from mastodon and woolly mammoth reveal deep speciation of forest and savanna elephants. PLoS Biol 8:16-19.

Rosin C, Poulsen JR, Swamy V, Granados A. 2017. A pantropical assessment of vertebrate physical damage to forest seedlings and the effects of defaunation. Glob Ecol Conserv 11:188-95.

Rowcliffe JM, Field J, Turvey ST, Carbone C. 2008. Estimating animal desnsity using camera traps without the need for individual recognition. J Appl Ecol 45:1228-36.

Schleppi P, Conedera M, Sedivy I, Thimonier A. 2007. Correcting non-linearity and slope effects in the estimation of the leaf area index of forests from hemispherical photographs. Agric For Meteorol 144:236-42.

Staver AC, Bond WJ, Cramer MD, Wakeling JL. 2012. Top-down determinants of niche structure and adaptation among African Acacias. Ecol Lett 15:673-9.

Stevens N, Lehmann CER, Murphy BP, Durigan G. 2017. Savanna woody encroachment is widespread across three continents. Glob Chang Biol 23:235-44.

Swanson A, Kosmala M, Lintott C, Simpson R, Smith A, Packer C. 2015. Snapshot Serengeti, high-frequency annotated camera trap images of 40 mammalian species in an African savanna. Sci Data 2:150026.

Terborgh J, Davenport LC, Niangadouma R, Dimoto E, Mouandza JC, Scholtz O, Jaen MR. 2016. Megafaunal influ- 
ences on tree recruitment in African equatorial forests. Ecography (Cop) 39:180-6.

Thimonier A, Sedivy I, Schleppi P. 2010. Estimating leaf area index in different types of mature forest stands in Switzerland: a comparison of methods. Eur Joural For Res 129:543-62.

Tutin C, Abernethy K, Jeffery K, Moussavou G, Mihindou V, Lehmann D, Edzang Ndong J, Starkey R, Malhi Y, Evouna Ondo F, Bush E, White L. 2016. Long-term climatic data-sets, SEGC, Lopé NP. Libreville, Gabon: Gabon.

Tutin C, Abernethy K, White L, Dimoto E, Dikangadissi J-T, Jeffery K, Momont L, Ukizintambara T, Bush E. 2018. Lopé Tree Phenology Dataset. Version 1.1. http://hdl.handle.net/ $11667 / 103$.

Tutin CEG, Fernandez M. 1993. Relationships between Minimum Temperature and Fruit Production in some Tropical Forest Trees in Gabon. J Trop Ecol 9:241-8.

van de Weghe JP. 2011. Les Parcs Nationaux du Gabon: Lopé, Waka et Monts Birougou. Libreville, Gabon: ANPN and WCS Gabon.

White F. 1983. The vegetation of Africa: A descriptive memoir to accompany the Vegetation Map of Africa.

White LJT. 1992. Vegetation history and logging disturbance: effects on rain forest in the Lope Reserve, Gabon (with special emphasis on elephants and apes).
White LJT. 1994a. Biomass of rainforest mammals in the Lope Reserve Gabon. J Anim Ecol 63:499-512.

White LJT. 1994b. Sacoglottis gabonensis fruiting and the seasonal movements of elephants in the Lopé Reserve. Gabon. J Trop Ecol 10:121.

White LJT, Tutin CE, Fernandez M. 1993. Group composition and diet of forest elephants Loxodonta africana cyclotis. Afr J Ecol 31:181-9.

White LJT, Tutin CEG, Fernandez M. 1994. Behavioural and dietary similarities of elephants and apes in the Lope Reserve, Gabon: Should forest elephants be re-classified as apes? Ecol Evol:19-27.

White LTJ. 2001. Forest-savanna dynamics and the origins of the Marantacea forest in central Gabon. In: Weber B, White L, Vedder A, Naugthon-Treves L, Eds. African Rain Forest Ecology and Conservation. New Haven, Conneticut: Yale University Press. p 165-82.

White LTJ, Abernethy KA. 1997. A guide to the vegetation of Lope Reserve Gabon. Libreville, Gabon: Multipress-Gabon.

Wing LD, Buss IO. 1970. Elephants and Forests. Wildl Monogr 19:3-92. 